\title{
RINOSPORIDIOSE NASAL - ESTUDO DE 11 CASOS
}

\author{
José Figuerêdo da Silva *, Wilton Mendes da Silva**, Arnoldo de Macêdo \\ Nogueira *** e Sebastião E. Cavalcante ****
}

Os $A$. A. apresentam 11 casos de rinosporidiose nasal, cuios aspectos clinicos, anatomo-patológicos e epidemiológicos são analisados. Os pacientes - um negro, um branco e nove de cor parda. todos ruricolas - tinham de 6 a 33 anos. Nove eram do sexo masculino. O tempo de evolução da doença variou de três meses a quatro anos e havia um caso com três recidivas. A grande maioria era proveniente do Maranhão.

\section{INTRODUÇÃO}

A rinosporidiose, ou Doença de SEEBER, é um processo inflamatório crônico, granulomatoso, que afeta o homem e, raramente, alguns animais como bovino, equino e muar. Embora tenham sido descritos casos com comprometimento de outros órgãos, exigindo por vezes intervençōes cirúrgicas delicadas (18), é mais comum nas mucosas do nariz e olho, onde provoca lesões polipóides ou vegetantes, sésseis ou pediculacias. Seu agente etiológico é o $R h i$ nosporidium seeberi (Wernicke, 1900, in Bélou, 19C3 $|9|$ ), um fungo classificado entre os Phycomycetes (5), embora esta posição taxonômica não esteja ainda definida (4). A observação inicial foi feita na Argentina por Malbran, que, em 1892, identificou o micro-organismo num polipo nasal humano, mas foi Seeber (24) quem primeiro o descreveu.

Apesar de sua distribuição cosmopolita, a rinosporidiose é mais frequente em regiões tropicais, como acontece na índia e no Ceilão. As fontes de infecção, modo de transmissão, os aspectos imunológicos, os animais susceptíveis à inoculaçāo experimental e os possíveis meios de cultura deste fungo são capítulos até o momento desconhecidos.

\section{MATERIAL}

O material, objeto do presente trabalho, consta de 11 pacientes atendidos e tratados pelo Serviço de Otorrinolaringologia do Hospital Getúlio Vargas, em Teresina Piauí, e procedentes dos Estados do Piauí e Maranhão (Quadro 1), no período de 13-9-72 a 26-7-74.

De acordo com a bibliografia consultada, a doença incide principalmente em pacientes jovens e em geral do sexo masculino (Quadro 2).

O paciente mais jovem tinha 6 anos de idade e o mais idoso, 33 (Quadro I). O tamanho das tumoraçōes, considerando-se o diâmetro longitudinal das mesmas, variou de $0,7 \mathrm{~cm}$ a $4,0 \mathrm{~cm}$. O menor período de evolução foi de 3 meses (com lesão de $4 \mathrm{~cm}$ ) e o maior 4 anos, correspondendo

* Professor Colaborador de Anatomia Patológica do Centro de Ciênclas da Saúde da Universidade Federal do Plauí - Patologista do Hospital Getúlio Vargas - Teresina.

* Médico do Serviço de O.R.L. do Hospital Getúlio Vargas.

*** Professores Colaboradores de O.R.L. do Centro de Clênclas da Saúde da Universidade Federal do Piauí.

Recebido para publicaçăo em 25/09/74. 
QUADRO 1 - Número de casos, idade, sexo, cor, ocupação, locali zação da lesão, evolução, dimensões da tumoração e procedência dos pacientes portadores de rincsporidiose atendidos e tratados no H.G.V., em Teresina - Piauí.

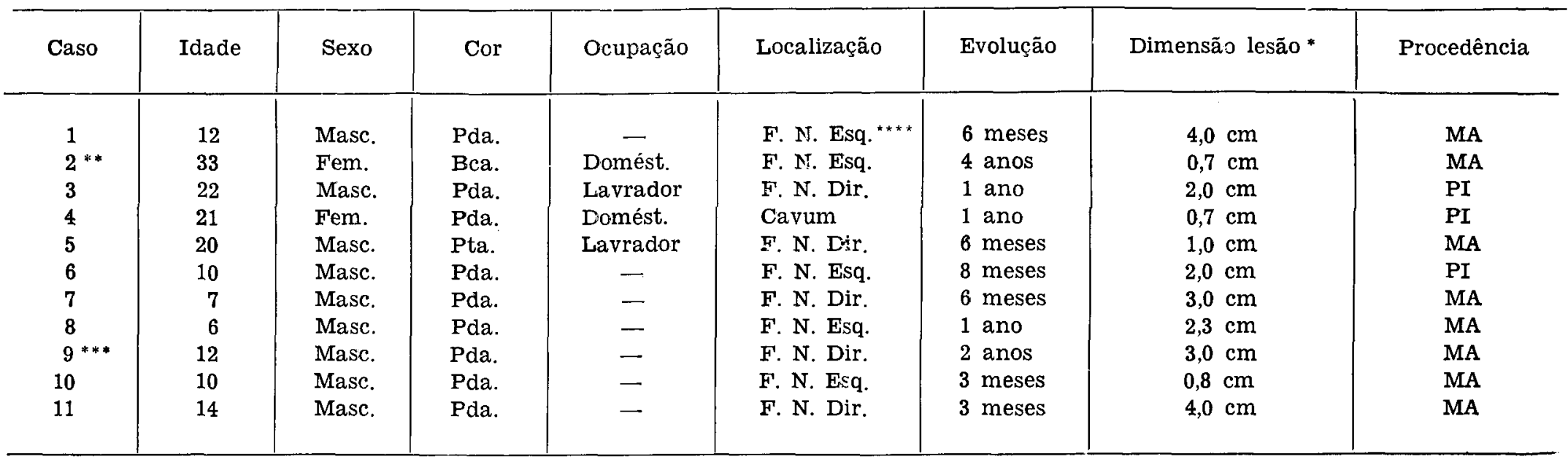

* As medidas correspondem ao maior diâmetro da lesão *** Caso referindo 3 recidivas.

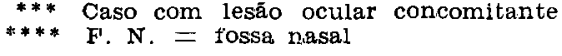


QUADRO 2 - Distribuição por grupo etário e sexo dos 11 casos de rinosporiơiose nasal.

\begin{tabular}{l|c|c|c}
\hline \multirow{2}{*}{ Idade } & \multicolumn{2}{|c|}{ Sexo } & \\
\cline { 2 - 4 } & Masc. & Fem. & Total \\
\hline Até 10 anos & 4 & - & \\
11 a 20 anos & 4 & - & 4 \\
21 a 30 anos & 1 & 1 & 2 \\
$31+$ & - & 1 & 1 \\
\hline
\end{tabular}

ao paciente mais idoso e referindo 3 recidivas (com lesão de $0,7 \mathrm{~cm}$ ), sugerindo não haver relação estreita entre a idade do paciente, o tempo de evolução e as dimensōes da tumoração. Ainda pelo Quadro 1 , com referência à localização da lesão, nota-se que a mesma não afeta simultaneamente as auas fossas nasais, havendo cinco casos na fossa nasal esquerda, cinco na direita e um atingindo o cavum. No caso 9 ocorria comprometimento simultâneo de conjuntiva tarsal superior do olho direito, tendo sido feita exerese da tumcração ocular e comprovado o diagnóstico pelo exame histopatológico. Todos os pacientes são rurícolas ou o eram na fase inicial da doença.

o estado geral dos pacientes era sempre muito bom, limitando-se a sintomatologia às áreas lesadas. Os sintomas mais importantes, presentes em todos os casos em intensidade variável, eram representados pela obstrução nasal total ou parcial, decorrente do crescimento progressivo $\mathrm{e}$ lento da tumoração, epistaxes, em geral de pequena monta, porém frequentes, muitas vezes secundárias ao ato ce assoar-se ou de espirrar. Alguns pacientes queixavamse de prurido inicial e apresentavam secreção muco-purulenta.

o tratamento em todos os casos foi cirúrgico: retirada da lesão e eletro-cauterização da base. Só um paciente voltou para ser reexaminado, não apresentando recidivas, dez meses após a cirurgia.

\section{ANATOMIA PATOLÓGICA}

Os aspectos anátomo-patológicos são inconfundiveis. Macroscopicamente (Fig. 1), os espécimes cirúrgicos fixados em formalina são branco-pardacentos, granulosos, ovóides e por vezes, devido à friabilidade, fragmentados. Em nosso material o diâmetro varia entre $0,7 \mathrm{~cm}$ e $4 \mathrm{~cm}$.

Em preparaçōes coradas pela hematoxilina-eosina e pelo P.A.S, o exame microscópico revela hiperplasia irregular do epitélio respiratório, que sofre metaplasia epidermóide (Fig. 2). O diagnóstico baseia-se na presença, no cório, de esporângios de cápsula quitinosa e tamanho variável, contendo esporos em várias fases de desenvolvimento. A quantidace de esporos é variáveì: em alguns cascs são muito numerosos (Fig. 2 e 3), tanto no interior dos esporângios como nos interstícios; em outros, são particularmente escassos (Fig. 4). De grande importância é a reação inflamatória que se estabelece difusamente, mas de caráter e intensidade nem sempre uniformes: em alguns casos predominam neutrófilos, por vezes condensacios em $\mathrm{mi}-$ croabscessos; em outros, salientam-se células gigantes tipo corpo estranho, dispostas em arranjo granulomatoso em torno de esporângios vazios (Fig. 4 e 5). Em todos os casos, todavia, estão presentes linfócitos, plasmócitos e histiócitos em maior quantidade. 


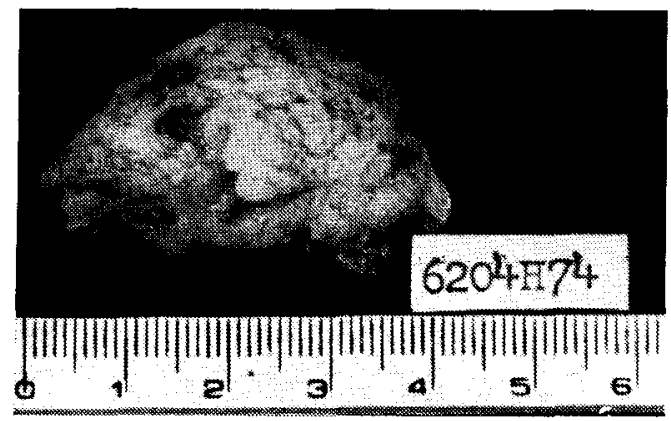

Fig. 1 - Aspecto macroscópico do polipo rinosporidiótico nasal (caso 11).

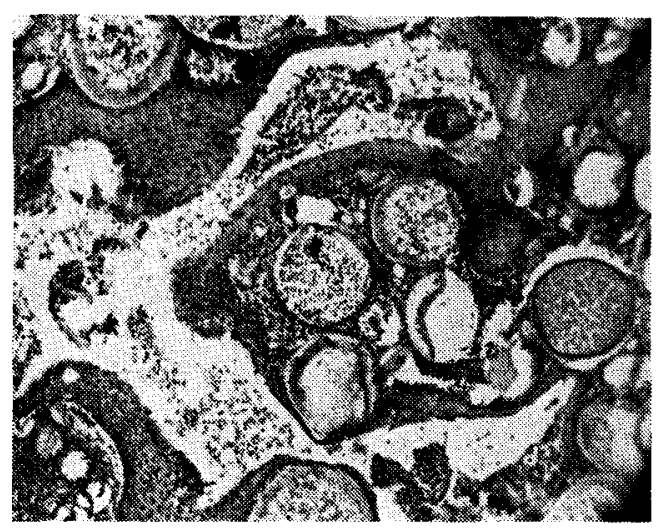

Fig. 2 - Aspectos microscópicos da rinosporidiose nasal: metaplasia epidermóide do epitélio respiratório e riqueza em esporângios (Caso 10 . H. E., $100 \mathrm{x}$ ).

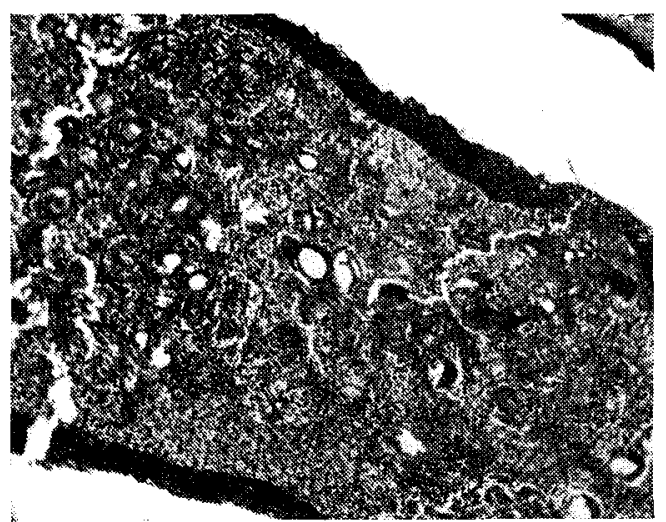

Fig. 4 - Esporângios com poucos esporos, colapsados, circundados por células gigantes tipo corpo estranho e infiltrado inflamatório mononuclear (Caso 1. H. E., $100 \mathrm{x}$ ).

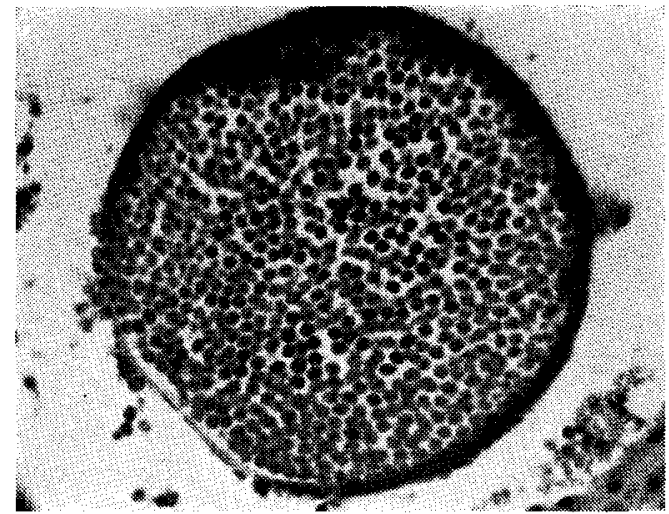

Fig. 3 - Esporângio (Caso 10. H. E, $1.000 \mathrm{x}$ ).

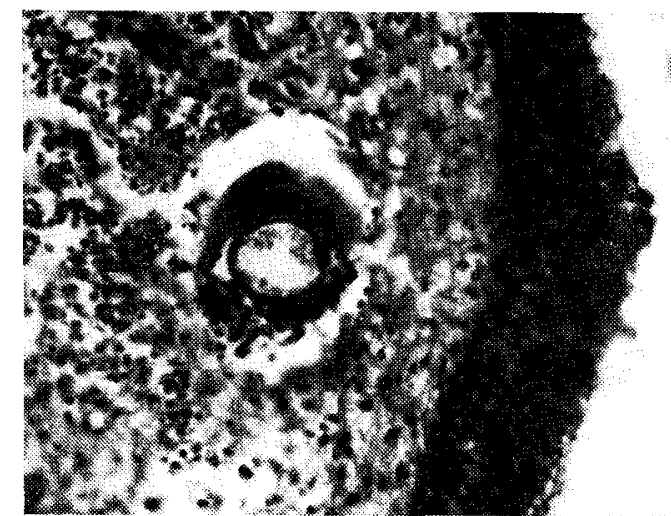

Fig. 5 - Detalhe da Fig. 4. Célula gigante tipo corpo estranho em torno de esporângio (Caso 1. H. E., $400 \mathrm{x}$ ). 


\section{COMENTÁRIOS E CONCLUSÕES}

A rinosporidiose é, em geral, uma doença benigna (18), de sintomatologia limita. da às áreas lesadas, de curso crônico, que pode durar anos. O tratamento de escolha é o cirúrgico, de vez que há pouca experiência referente ao uso de quimioterápicos (14), dando bons resultado desde que as lesōes sejam recentes e não disseminadas (3). O diagnóstico clínico é "viável, uma vez que se proceda a minuciosa anamnese e que se procure observar as particularidades de forma e aspecto que o tumor apresenta" (12), mesmo porque nenhuma outra doença se lhe assemelha (3).

Ao exame rinoscópico as lesões se apresentam polipóides, sésseis ou pediculadas, avermelhadas e com finas granulaçōes branco-amareladas, que correspondem a esporângios ou a micro-abcessos. Inicialmente únicas, podendo ser multifocais nos casos de longa duração. Quase sempre se mostram sangrantes, coincidindo haver secreção espessa, algumas vezes purulenta.

os achadcs anatomo-patológicos são característicos, nāo oferecendo dificuldades para o seu reconhecimento $(13,15)$, baseando-se o diagnóstico na presença do fungo nos tecidos. Na fase inicial do ciclo evolutivo, conforme os trabalhos de Asworth (5), Mello (17, 18) e Azevedo (6), o fungo se caracteriza como uma célula ovóide ou redonda, medindo 5 a $8 \mu$ e apresentando citoplasma claro, vacuolizado e cápsula quitinosa. Em decorrência de divisões mitóticas sucessivas, o parasita aumenta bastante de tamanho ,configurando-se o ascocarpo ou esporângio, que pode atingir um diâmetro de 200 a $300 \mu$ e conter até 16.000 esporos. Estes, quando maduros, abandonam o esporângio através de uma abertura pré-existente, a micrópila, ou por pontos de rotura na parede celulósica (10). Atingindo os interstícios, poderäo reiniciar o ciclo vital ou serem eliminados pelas secreçōes. As lesões tendem a permanecer limitadas, sendo raros os casos generalizados $(2,20)$.

A reação inflamatória que se estabelece parece mais estar relacionada com o ciclo evolutivo do parasita e com as defesas imunológicas do paciente, do que com a duração do parasitismo e em nosso material não consignamos variações significativas ao relacionarmos os quadros histológicos com o tempo de evolução.
Evidenciamos uma reação inflamatória crônica de base, caracterizada por número variável de linfócitos, plasmócitos $\mathrm{e}$ histiócitos, sobrepondo-se a isso focos de exsudação neutrofílica mais ou menos acentuados. Variações desse aspecto parecem depender do número de esporângios maduros. Como já assinalaram Barros Coelho $(7,8)$ e Coutinho (11), ocorre exsudação neutrofílica quando os esporos abandcnam o ascocarpo ,liberando substâncias tóxicas e determinando uma agudização do processo inflamatório. Por outro lado, afirmam Cantídio e Cols. (10), o número de formas evolutivas do fungo seria delimitado pelos elementos produtivos da reação inflamatória, que representariam a capacidade de cefesa imunológica. Confirmamos a opinião desses autores no que se refere às células gigantes: são de tipo corpo estranho e tanto mais abundantes quanto menor for o número de esporos e desse modo seria uma evidência da capacidade de defesa orgânica.

o primeiro caso de rinosporidiose no Brasil foi assinalado em 1930 por Montenegro, em São Paulo, tendo sido referido segundo Barros Coelho, por Fonseca em 1930 e Almeida em 1933. Os três casos seguintes foram publicados respectivamente por Fialho e Cols. (13), Barros Coelho (7) e Aben-Athar (1). De um modo geral, é considerada rara em nosso meio. De acordo com Cantídio e Cols. (10), até 1961 haviam sido descritos 23 casos, 10 dos quais provenientes do Nordeste, o que levou aqueles autores a sugerirem a possibilidade de estudos epidemiológicos visando a existência cie condiçóes geográficas especiais para a transmissão da doença. Trabalhos recentes parecem apoiar a hipótese de que a rinosporidiose ocorre em alta incidência em algumas regiōes nordestinas, talvez mesmo em forma endêmica. Miziara e Cols. (19), estudando 10 casos surgidos entre 20-10-65 e 27-06-72, salientam o fato de que 6 são originários do Maranhão, de onde já tinham sido descritos 2 casos anteriores (24). Ribeiro Gonçalves (22), da Clínica Oftalmológica do Hcspital Getúlio Vargas de Teresina, PI, em 11 casos de rinosporidiose ocular (dos quais sete diagnosticados histologicamente por um de nós - J.F.S.), encontra nove maranhenses e apenas dois piauienses. A esses 11, podemos acrescentar sete novos casos oculares, dos quais cinco procedem do Ma- 
ranhão. Se consideramos conjuntamente os 29 pacientes com rinosporidiose ocular e nasal tratados em Teresina, verificamos que 22 são provenientes do Maranhão e sete do Piauí. Como afirmam Allen e Dave (3), a rinosporidiose pode ser de grancie importância local. Na realidade, impõe-se no diagnóstico diferencial com as demais tumorações nasais (16), sendo o exame histológico uma necessidade imperiosa (21). E mesmo possível que a pre- valência real seja maior do que a consignada na literatura, lembram Mansur e Cols. (16), uma vez que nem sempre se procede a exame histológico de rotina.

\section{AGRADECIMENTOS}

Aos professores Paulo Zabulon de Figueirêdo e Maria Abigail Barbosa pela valiosa orientação. Aos srs. Hamílton Ferro e Airon Mendes, pelos serviços fotográficos e cie datilografia, respectivamente.

\section{$S U M M A R Y$}

The A. A. present it cases of rhinosporidiosis. The clinical, pathological and epidemiological aspects are studied. The pacients - a black man, a white woman and eight of brown color - were all of rural origin and the age ranged from 6 to 33 years. Nine were male. The duration of the disease varied from three months to four years and there was a case with three recurrences. The high prevalence of the disease in the State of Maranhão (Brazil) is emphasizer.

\section{REFERÊNCIAS BIBLIOGRÁFICAS}

1. ABEN-ATHAR, J. - "Um caso de rhinosporidiose". Rev. do Acadêmico de Medicina (Pará), 2: 2, 1944.

2. AGRAWAL, S., SHARMA, K.D. \& SHRIVASTAVA, J.B. - “Generalized rhinosporidiosis with visceral involvement". A. M. A. Arch. Dermat., 80: $22,1959$.

3. ALIEN, R.R.W.K. \& DAVE, M.L. "The treatment of Rhinosporidiosis in man based on the study of sixty cases". Indian Med. Gaz., 71: 376395.

4. ANGULO O., A. \& MONTEIRO LEITE, J. _- "Enfermidades producidas por hongos". In CORREA, P., ARIAS STELLA, J., PÉREZ TAMAYO, R. \& CARBONELL, L. - "Texto de Patologia”, México, La Prensa Médica Mexicana, 1970 , p. 270.

5. ASHWORTH, J.H. - "On Rhinosporidium seeberi with special reference to its spolulation and affinities". Trans. Royal Soc. Edimb., 53: 101, 1923.

6. AZEVEDO, P.C. - "Rhinosporidium Seeberi. Considerações sobre morfologia, ciclo parasitário e posição sistemática”. Tese. Pará, Ed. Gráfica Piratininga, Ltda., 1958.

7. BARROS COELHO - "Um caso de rhinosporidiose nasal". Res. Clín. Cient, 11: 521, 1942.
B. - - "Rhinosporidiose". An. Fac. de Medicina da Universidade do Recife, 12-13: 5, 1945, 1946.

9. BELOU, P. - "Tratado de Parasitologia Animal". Buenos Aires, 1903, in (5).

10. CANTIDIO, W., PINHEIRO, G. \& TOMÉ, G. - "Rinosporidiose". Rev. Fac. Med. Univ. Ceará, 1: 79, 1961.

11. COUTINHO, E.M. - "Rhinosporidiose". An. Fac. Med. Univ. Recife, 15: $41,1955$.

12. FERREIRA FILHO, M.A. \& MONTEIRO SALLES, F.J. - "Rinosporiodose nasal". Ar. Inst. Penido Burnier, 8: 104, 1949 .

13. FIALHO, A., SILVEIRA, A. SAMPAIO, G. \& CHAVES, V. - "Um caso de rinosporidiose nasal". Hospital (Rio), 17: 945, 1940.

14. HILDICK-SMITH, G., BLANK, H. \& SARKANY, I. - "Fungus disease and their treatment". Boston, Little, Brown and Company, 1954, p. 342.

15. LACAZ, C.S. - "Micologia Médica". São Paulo, Sarvier — Instituto Nacional do Livro/M.E.C., 5. ${ }^{\text {a }}$ Edição, 1973, p. 290 .

16. MANSUR, E., MION, D., PAIVA, L.J., MONTINI, A. \& CARVALHO, W.R. - "Rinosporidiose Nasal". Rev. Rerap. Brasil., 2: 185, 1968. 
17. MELLO, M.T. - "Estudos sobre o Rhinosporodium Seeberi". Tese. Escola Nacional de Veterinária, Rio, 1946.

18. _- "Rhinosporidiosis", Mycopath. et Mycol. Appl., 4: 342, 1949.

19. MIZIARA, H.L., SANTOS, F.A.M \& KALI, R.K. - "Rinosporidiose Nasal - Aspectos epidemiológicos e anatomo-patológicos em 10 casos". Rev. Pat Trop., 1: 473, 1972.

20. NGUYEN VAN UT, N. GUYEN VAN AI, NGUYEN TRI LOC, NGUYEN LOU VIEN \& TRAN-NGOG NIHN "Un cas de rhinosporidiose nasale, cutaneé et osseuse". La Fresse Medicale, 67: 2 073, 1959.
21. OLIVEIRA, N.F.S. \& VIEIRA, C.B.B. - "Rinosporidiose Nasal". Rev. Brasil.. Oto-Rino-Larin., 38: 143, 1972.

22. RIBEIRO GONÇALVES, J.O. Anais dio XVII Congresso Brasileiro de Oftalmologia”, Salvador, 7-9 de setembro de 1973.

23. SANTOS, F.M. - "Comunicação de 2 cascs de rinosporidiose". Congresso Regional Norte-Nordeste de Patologia, Natal, 1ะ67.

24. SEEBER, G.R. - "Um nuevo esporozoario parásito del hombre. Dos casos encontracios em polipos nasales" - Tesis. Univ. Nac. Buenos Aires, Argentina, 1900 - In (5). 